\title{
Output-Feedback Nonlinear Adaptive Control Strategy of the Single-Phase Grid-Connected Photovoltaic System
}

\author{
Abdelmajid Abouloifa, ${ }^{1}$ Chaouqi Aouadi $\mathbb{D}^{1},{ }^{1}$ Ibtissam Lachkar, ${ }^{2}$ Yasser Boussairi, ${ }^{1}$ \\ Meriem Aourir, ${ }^{1}$ and Abdellatif Hamdoun ${ }^{1}$ \\ ${ }^{1}$ LTI Lab, Faculty of Sciences Ben M'sik, University Hasan II of Casablanca, 7955 Casablanca, Morocco \\ ${ }^{2}$ LRI Lab, ENSEM of Casablanca, University Hasan II of Casablanca, 7955 Casablanca, Morocco \\ Correspondence should be addressed to Chaouqi Aouadi; aouadi.chaouki@gmail.com
}

Received 13 September 2017; Revised 10 November 2017; Accepted 21 January 2018; Published 8 March 2018

Academic Editor: Sundaram Senthilarasu

Copyright (C) 2018 Abdelmajid Abouloifa et al. This is an open access article distributed under the Creative Commons Attribution License, which permits unrestricted use, distribution, and reproduction in any medium, provided the original work is properly cited.

\begin{abstract}
This paper addresses the problem of controlling the single-phase grid connected to the photovoltaic system through a full bridge inverter with LCL-filter. The control aims are threefold: (i) imposing the voltage in the output of PV panel to track a reference provided by the MPPT block; (ii) regulating the DC-link voltage to guarantee the power exchange between the source and AC grid; (iii) ensuring a satisfactory power factor correction (PFC). The problem is dealt with using a cascade nonlinear adaptive controller that is developed making use of sliding-mode technique and observers in order to estimate the state variables and grid parameters, by measuring only the grid current, PV voltage, and the DC bus voltage. The control problem addressed by this work involves several difficulties, including the uncertainty of some parameters of the system and the numerous state variables are inaccessible to measurements. The results are confirmed by simulation under MATLAB $\backslash$ Simulink $\backslash$ SimPowerSystems, which show that the proposed regulator is robust with respect to climate changes.
\end{abstract}

\section{Introduction}

The global concern about climate change and the growing energy demand of industrialized countries have necessarily led to exploring other new sources like the renewable energy. The main advantages of this type of renewable energies reside in the reduction of pollution caused by the production of greenhouse gases. Among different types of these energies, the photovoltaic energy has obtained a great attention.

The photovoltaic energy systems are classified according to their use. The two principal classifications are gridconnected systems and stand-alone systems. The first one is connected to the grid through a three-phase or single-phase inverter; this category is used to deliver the power directly to utility grid and must be properly controlled according to power electrical legislations. The second one is used with a battery bank for electrifying remote rural areas.

The power factor correction, the DC output voltage regulation, and the maximization of the power provided by the PV modules are the main control objectives for allowing high power quality to the grid. To meet these requirements, various control methods have been proposed in [1-3]. Indeed, [4] proposed a passivity based control. However, this technique requires being in a passive state. In [5], the proportional resonant (PR) controller is designed. The latter provides acceptable dynamic performance and eliminates the steady-state error. In [6, 7] a sliding-mode controller (SMC) is used to have an excellent robustness and a very good steady-state performance as well as a fast-dynamic response. In [8] the authors propose a control law based on backstepping [9] and Lyapunov function so as to stabilize the global system.

In the literature, a few papers dealt with state-feedback control [10] and state observer design at the same time. In [11] a state-feedback control law is combined with observer to enhance disturbance rejection capability of a grid-connected photovoltaic inverter. In order to achieve the third goal, it is important that the PV system operates at its optimal power 


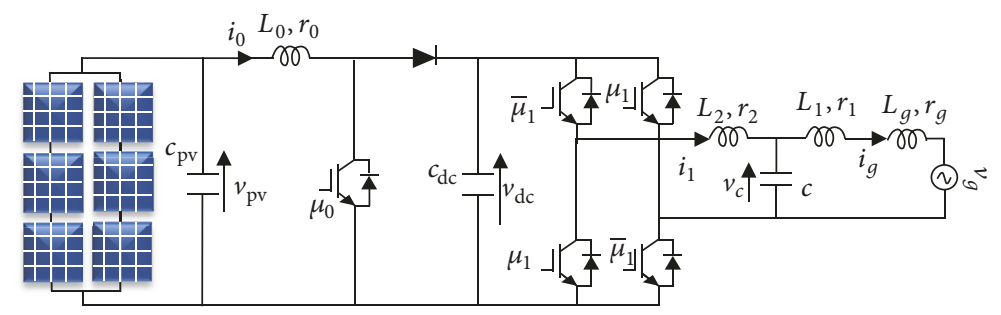

FIGURE 1: Photovoltaic system tied to the single-phase grid.

point, and for this task a maximum power point tracking is required.

In this work, we seek a control strategy that meets the following three control objectives simultaneously:

(i) Perfect power factor correction (PFC): the grid phase currents and its corresponding voltages must be in phase.

(ii) DC output voltage regulation: this voltage must be tightly regulated to a constant reference value to ensure the power exchange between AC grid and the DC bus.

(iii) Maximization of the power provided by the PV models.

To achieve the above objectives, a cascaded nonlinear adaptive controller is designed. The latter is constituted by a PV voltage loop and grid current loop. The first one is designed to extract the maximum power from the PV array by regulating the voltage provided by the PV generator. The second one includes the inner loop and aims to regulate the grid current to meet the PFC, and the outer loop is intended to enhance the power exchange, between the source and the grid, by regulating the DC-link voltage. These loops are designed based on sliding-mode technique combined with a Luenberger and extended Kalman filter type. Compared to previous works, the contribution of the present study enjoys several interesting features including the following:

(i) Several control objectives are simultaneously considered (MPPT, DC Regulation, and PFC) while only some of these objectives have been tackled in previous works $[12,13]$.

(ii) The nonlinearity of the controlled system was preserved [14] in order to keep all the properties of the studied system.

(iii) The grid voltage is not accessible to measurement and the internal impedance is assumed to be unknown, unlike previous works which assumed that voltage is available and the grid impedance is null or known [15-17].

(iv) The present nonlinear adaptive control system does not necessitate many sensors for the measurement of some needed variables unlike previous works [18].

The paper is structured as follows: in Section 2, a mathematical model and description of all system stage are described. In Section 3, the design of the cascade nonlinear adaptive controller is presented. Section 4 covers the simulation results and discussion about the results. The conclusion is in the end.

\section{System Description}

This section describes the modelling of photovoltaic system connected to the grid. The power plant under study is shown in Figure 1. It consists of a PV panel, a DC-DC boost converter that drains the energy from the photovoltaic module and feed the DC bus capacitor, and a full bridge single-phase inverter with LCL-filter used at the output of the converter to achieve a satisfactory total harmonic distortion of the injected current.

By analyzing the circuit and applying the well-known Kirchhoff laws, the equations describing the dynamics of the system of Figure 1 are given below:

$$
\begin{aligned}
\left(L_{g}+L_{1}\right) \frac{d i_{g}}{d t} & =v_{c}-v_{g}-\left(r_{g}+r_{1}\right) i_{g} \\
C \frac{d v_{c}}{d t} & =i_{1}-i_{g} \\
L_{2} \frac{d i_{1}}{d t} & =\mu_{1} v_{\mathrm{dc}}-v_{c}-r_{2} i_{1} \\
C_{\mathrm{pv}} \frac{d v_{\mathrm{pv}}}{d t} & =i_{\mathrm{pv}}-i_{0} \\
L_{0} \frac{d i_{0}}{d t} & =v_{\mathrm{pv}}-\left(1-\mu_{0}\right) v_{\mathrm{dc}}-r_{0} i_{0} \\
C_{\mathrm{dc}} \frac{d v_{\mathrm{dc}}}{d t} & =\left(1-\mu_{0}\right) i_{0}-\mu_{1} i_{1}
\end{aligned}
$$

or $v_{\mathrm{pv}}$ and $i_{\mathrm{pv}}$ are the voltage and the current generated by $\mathrm{PV}$ array, $v_{\mathrm{dc}}$ is DC-link voltage, $i_{g}$ and $v_{g}$ are the current and voltage of the grid, $i_{0}$ designates the input current chopper, and $\mu_{0}$ and $\mu_{1}$ are the switching functions given by

$$
\begin{aligned}
& \mu_{0}= \begin{cases}1 & \text { if } s_{0} \text { is ON } \\
0 & \text { if } s_{0} \text { is OFF, }\end{cases} \\
& \mu_{1}= \begin{cases}1 & \text { if }\left(s_{1}, s_{4}\right) \text { is } \mathrm{ON},\left(s_{2}, s_{3}\right) \text { is OFF } \\
-1 & \text { if }\left(s_{1}, s_{4}\right) \text { is } \mathrm{OFF},\left(s_{2}, s_{3}\right) \text { is ON. }\end{cases}
\end{aligned}
$$


TABLE 1: State variables and unknown parameters.

\begin{tabular}{lcc}
\hline $\begin{array}{l}\text { Variables and } \\
\text { parameters }\end{array}$ & Definition & Observation \\
\hline$x_{1 r}$ & $v_{g} /\left(L_{1}+L_{g}\right)$ & $\begin{array}{c}\text { Nonaccessible to } \\
\text { measurements }\end{array}$ \\
$x_{2 r}$ & $\dot{v}_{g} /\left(L_{1}+L_{g}\right)$ & $\begin{array}{c}\text { Nonaccessible to } \\
\text { measurements }\end{array}$ \\
$\theta_{1}$ & $\left(r_{1}+r_{g}\right) /\left(L_{1}+L_{g}\right)$ & Unknown parameter \\
$\theta_{2}$ & $1 /\left(L_{1}+L_{g}\right)$ & Unknown parameter \\
\hline
\end{tabular}

The above instantaneous model (1a)-(1f) cannot be used directly for controller design as it involves the binary inputs, namely, $\mu_{0}$ and $\mu_{1}$. To overcome this problem, let us use the averaging model (3a)-(3f). The state variables $i_{g}, v_{c}, i_{1}, v_{\mathrm{pv}}$, $i_{0}$, and $v_{\mathrm{dc}}$ are replaced by their average values $x_{1}, x_{2}, x_{3}, x_{4}$, $x_{5}$, and $x_{6}$ over a cutting period. The control inputs $u_{0}$ and $u_{1}$ denote the average values of $\mu_{0}$ and $\mu_{1}$, respectively.

$$
\begin{aligned}
\dot{x}_{1} & =-\theta_{1} x_{1}-x_{1 r}+\theta_{2} x_{2} \\
C \dot{x}_{2} & =x_{3}-x_{1} \\
L_{2} \dot{x}_{3} & =u_{1} x_{6}-x_{2}-r_{2} x_{3} \\
C_{\mathrm{pv}} \dot{x}_{4} & =i_{\mathrm{pv}}-x_{5} \\
L_{0} \dot{x}_{5} & =x_{4}-\left(1-u_{0}\right) x_{6}-r_{0} x_{5} \\
C_{\mathrm{dc}} \dot{x}_{6} & =\left(1-u_{0}\right) x_{5}-u_{1} x_{3}
\end{aligned}
$$

The supply net voltage $v_{g}$ is considered inaccessible to measurement. Equation (3a) is completed with the internal model of the grid voltage signal $v_{r}=E_{g} \sin \left(\omega_{r} t\right)$. In particular,

$$
\begin{aligned}
\frac{d^{2} v_{r}}{d t^{2}} & =\omega_{r}^{2} v_{r} \\
\dot{x}_{1 r} & =x_{2 r} \\
\dot{x}_{2 r} & =\omega_{r}^{2} x_{1 r},
\end{aligned}
$$

where $E_{g}$ and $\omega_{r}$ denote, respectively, the amplitude and the angular frequency of $v_{r}$. The inaccessible states and unknown parameters are presented in Table 1.

\section{Control Strategies of the System}

In this section, an output-feedback nonlinear controller will be synthetized. As represented by the averaging model (3a)-(3f) the system has two control inputs $\left(u_{0}, u_{1}\right)$. The controllers (Figure 2) will be designed to achieve the three main objectives mentioned previously.

In addition, the observers are designed to estimate the values of unmeasurable states. The first task is dedicated to the design of the observers and the second task is devoted to development of an output-feedback nonlinear controllers.
3.1. State Observer Design. The purpose of the present subsection is to design the observers, which provide accurate estimates of states variables and use them later to develop an output-feedback controller such that the estimation errors converge to zero. For that, an adaptive observer and Luenberger observer [19] are designed to estimate the state variables $\left(x_{1}, x_{2}, x_{3}, x_{4}\right.$, and $\left.x_{5}\right)$ based only on the measurement of the states $\left(x_{1}, x_{4}\right)$.

The model described by (3a)-(3f) can be given in the following two subsystems, denoted by $\Sigma_{1}$ and $\Sigma_{2}$ with

$$
\begin{gathered}
\Sigma_{1}:\left\{\begin{array}{l}
\dot{X}_{1}=A_{1} X_{1}+\phi_{1}\left(u_{1}, x_{6}\right) \\
y_{1}=C_{1} X_{1}
\end{array}\right. \\
\Sigma_{2}:\left\{\begin{array}{l}
\dot{X}_{2}=A_{2}\left(u_{0}\right) X_{2}+\phi_{2} \\
y_{2}=C_{2} X_{2}
\end{array}\right.
\end{gathered}
$$

where

$$
\begin{aligned}
& X_{1}=\left[\begin{array}{l}
x_{1} \\
x_{2} \\
x_{3}
\end{array}\right] \text {, } \\
& A_{1}=\left[\begin{array}{ccc}
-\frac{r_{1}}{L_{1}} & \frac{1}{L_{1}} & 0 \\
-\frac{1}{C} & 0 & \frac{1}{C} \\
0 & -\frac{1}{L_{2}} & -\frac{r_{2}}{L_{2}}
\end{array}\right] \text {, } \\
& C_{1}^{T}=\left[\begin{array}{l}
1 \\
0 \\
0
\end{array}\right], \\
& \phi_{1}\left(u_{1}, x_{6}\right)=\left[\begin{array}{c}
-\frac{v_{g}}{L_{1}} \\
0 \\
u_{1} x_{6}
\end{array}\right] \\
& X_{2}=\left[\begin{array}{l}
x_{4} \\
x_{5}
\end{array}\right] \text {, } \\
& A_{2}=\left[\begin{array}{cc}
0 & -\frac{1}{C_{\mathrm{pv}}} \\
\frac{1}{L_{0}} & -\frac{r_{0}}{L_{0}}
\end{array}\right] \text {, } \\
& C_{2}^{T}=\left[\begin{array}{l}
1 \\
0
\end{array}\right], \\
& \phi_{2}=\left[\begin{array}{c}
i_{\mathrm{pv}} \\
C_{\mathrm{pv}} \\
0
\end{array}\right] \text {. }
\end{aligned}
$$

Obviously $y_{1}=x_{1}$ and $y_{2}=x_{4}$ are the measured output of the PV system connected to the grid. 


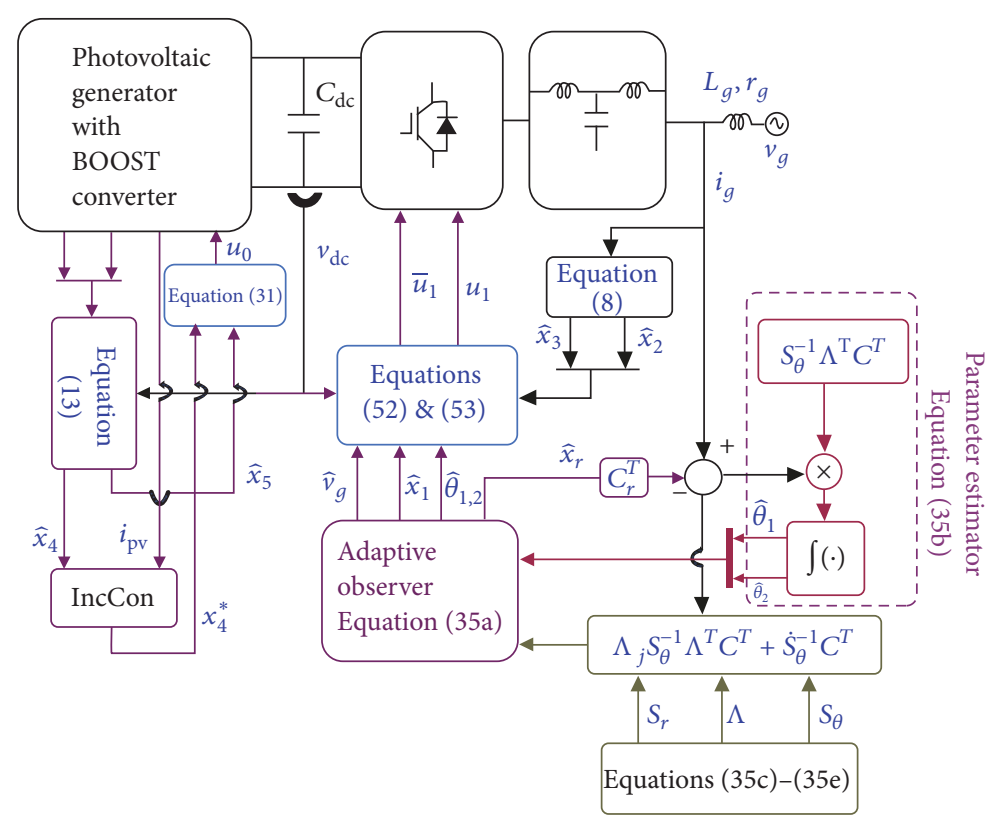

FIGURE 2: Schematic diagram of nonlinear adaptive controller.

The design strategy consists in synthesizing separately an observer for each one of subsystems (6a)-(6b). In the first step, a linear observer is designed for subsystem $\Sigma_{1}$. In the second step, an adaptive observer is designed for subsystem $\Sigma_{2}$.

3.1.1. Linear Observer. The form of system $\Sigma_{1}$ suggests the following Luenberger observer for the estimation of the unknown state variables $\left(x_{1}, x_{2}, x_{3}\right)$ :

$$
\begin{aligned}
& \dot{\bar{X}}_{1}=A_{1} \widehat{X}_{1}+\phi_{1}\left(u_{1}, x_{6}\right)+K_{1}\left(y_{1}-C_{1} \widehat{X}_{1}\right) \\
& \widehat{y}_{1}=C_{1} \widehat{X}_{1}
\end{aligned}
$$

where $K_{1}=M C_{1}=\left[\begin{array}{l}\eta_{\eta_{11}} \\ \eta_{12} \\ \eta_{13}\end{array}\right]$ are the observer gain.

From (6a) and (8) one obtains the estimation error dynamics:

$$
\dot{e}_{1}=A_{0} e_{1}
$$

with $e_{1}=x_{1}-\hat{x}_{1}$.

The gain vector $M$ is selected to make $A_{0}=A_{1}-M C_{1}$ a Hurwitz matrix, which will guarantee the asymptotic error convergence.

Introduce the following Lyapunov function candidate:

$$
f_{l}=e_{1}^{T} Q e_{1},
$$

where $Q$ is asymmetric positive definite matrix. The derivative of $f_{l}$ along the trajectory of $e_{1}$ is given by

$$
\frac{d f_{l}}{d t}=e_{1}^{T}\left(A_{0}^{T} Q+Q A_{0}\right) e_{1} .
$$

The $Q$ matrix is chosen as $A_{0}^{T} Q+Q A_{0}=-I$, where $I$ denotes the identity matrix, and this choice leads to

$$
\frac{d f_{l}}{d t}=-e_{1}^{T} \quad e_{1}<0
$$

3.1.2. Adaptive Observer. The system $\Sigma_{2}$ is state-affine in the sense that all unknown states come in linearly. According to the [18] methodology the following adaptive observer is developed to estimate the state variables for subsystem $\Sigma_{2}$ :

$$
\begin{aligned}
\dot{X}_{2} & =A_{2} \widehat{X}_{2}+\phi_{2}+P_{X_{2}}^{-1} C_{2}^{T}\left(y_{2}-C \widehat{X}_{2}\right) \\
\widehat{y}_{2} & =C_{2} \widehat{X}_{2}
\end{aligned}
$$

where $P_{X_{2}}$ is the solution of the fallowing equation:

$$
\begin{aligned}
\dot{P}_{X_{2}} & =-\gamma P_{X_{2}}-A_{2}{ }^{T} P_{X_{2}}-P_{X_{2}} A_{2}+C_{2}^{T} C_{2} \\
P_{X_{2}}(0) & >0 .
\end{aligned}
$$

The matrix $P_{X_{2}}$ is ensured bounded positive definite provided the following persistent excitation condition holds:

$$
\alpha_{1} I \leq \int_{t}^{t+T} \phi_{u_{0}}(\tau)^{T} C_{2}^{T} \Sigma C_{2} \phi_{u_{0}}(\tau) d \tau \leq \beta_{1} I
$$

$$
\forall t \geq t_{0}
$$

for some constants $\left(\alpha_{1}, \beta_{1}, T\right)>0$, where $\phi_{u_{0}}(\tau)$ denotes the transition matrix for the subsystem $\dot{X}_{2}=A_{2}\left(u_{0}\right) X_{2}, y_{2}=$ $C_{2} X_{2}$, and $\Sigma$ is a positive definite bounded matrix. The system can be seen as a linear time-varying system parameterized by initial conditions as soon as the function $u_{0}$ is fixed. 
To study the convergence of the proposed observer (13), defining the estimation error as

$$
\widetilde{X}_{2}=X_{2}-\widehat{X}_{2}
$$

its dynamics are given by

$$
\dot{\widetilde{X}}=\left(A_{2}\left(u_{0}\right)-P_{X_{2}}^{-1} C_{2}^{T} C_{2}\right) \widetilde{X}_{2} .
$$

Proof. To analyze the error system (17), the following Lyapunov function candidate is considered:

$$
W\left(\widetilde{X}_{2}\right)=\widetilde{X}_{2}^{T} P_{X} \widetilde{X}_{2}
$$

Its time derivative is given by

$$
\begin{aligned}
\dot{W}\left(\widetilde{X}_{2}\right) & =\widetilde{X}_{2}^{T}\left(-\gamma P_{X}-C^{T} C\right) \widetilde{X}_{2}<-\widetilde{X}_{2}^{T} \gamma P_{X} \widetilde{X}_{2} \\
& =-\rho W\left(\widetilde{X}_{2}\right),
\end{aligned}
$$

where $\rho=\min (\gamma)$ and $\gamma$ are any positive constants.

Proposition 1. Under condition (15), the estimation error (17) is exponentially vanishing; that is, the estimate $\widehat{X}_{2}$ converges exponentially to its true value $X_{2}$ with a rate driven by $\gamma$ [19].

3.2. Output-Feedback Controller. The PV output voltage $x_{4}$ is regulated by controlling the switching device of the boost converter, while the DC-link voltage $x_{6}$ and the grid current $x_{1}$ are adjusted through the switching devices of the inverter.

3.2.1. Control of Boost Chopper (PV Voltage Controller). The control objective is to enforce the voltage provided by the PV panel to track the desired signal in order to achieve maximum power point. This regulator consists of two loops: a loop for seeking of the nominal power point, in which we used the IncCond algorithm, and a loop for regulating the voltage $\widehat{x}_{4}$. Then, to reach these aims, we seek a control law of slidingmode type. This law takes the following form:

$$
u_{0}=u_{0 \mathrm{eq}}+u_{0 N}
$$

where $u_{0 \text { eq }}$ is nominal control, it keeps the system on the sliding surface, and $u_{0 N}$ is discontinuous control, and it allows to reach the sliding surface.

To design a controller for subsystem (3d)-(3e), the error is defined as follows:

$$
e_{1}\left(x_{4}\right)=\widehat{x}_{4}-x_{4}^{*}
$$

Its dynamic are

$$
\dot{e}_{1}\left(\widehat{x}_{4}\right)=\frac{1}{C_{\mathrm{pv}}} i_{\mathrm{pv}}-\frac{1}{C_{\mathrm{pv}}} \widehat{x}_{5}-\dot{x}_{4}^{\mathrm{ref}} .
$$

In order to stabilize subsystem (3d)-(3e), the slidingmode control technique is used. The sliding surface is defined as follows:

$$
S_{1}(\widehat{x})=\dot{e}_{1}\left(\widehat{x}_{4}\right)+\delta e_{1}\left(\widehat{x}_{4}\right),
$$

where $\delta$ is the parameter of the sliding surface.
The dynamics of the surface are given by

$$
\begin{aligned}
\dot{S}_{1}(\widehat{x})= & \frac{1}{C_{\mathrm{pv}}} \dot{i}_{\mathrm{pv}}+\frac{1}{C_{\mathrm{pv}} L_{0}}\left(-\widehat{x}_{4}+r_{0} \widehat{x}_{5}+x_{6}\right) \\
& -\frac{x_{6}}{C_{\mathrm{pv}} L_{0}} u_{0}-\frac{\varsigma_{21}}{C_{\mathrm{pv}}} \varsigma_{21} \widetilde{X}_{2}+\delta \dot{x}_{4}-\ddot{x}_{4}^{*}-\delta \dot{x}_{4}^{*} .
\end{aligned}
$$

The equivalent command $u_{0 \text { eq }}$ is calculated by means of the method of "Utkin"; setting the sliding surface $\dot{S}_{1}(x)=0$, the nominal control law can be defined as

$$
\begin{aligned}
& u_{0 \mathrm{eq}}=1-\frac{1}{x_{6}}\left(L_{0} \dot{i}_{\mathrm{pv}}-\widehat{x}_{4}+r_{0} \widehat{x}_{5}-\varsigma_{21} L_{0} \widetilde{X}_{2}\right. \\
& \left.+L_{0} C_{\mathrm{pv}}\left(\delta \dot{x}_{4}-\ddot{x}_{4}^{*}-\delta \dot{x}_{4}^{*}\right)\right)
\end{aligned}
$$

and, to elaborate the discontinuous control, consider the following Lyapunov function candidate:

$$
v_{1}=\frac{1}{2} S_{1}^{2}
$$

and its dynamics are given by

$$
\dot{v}_{1}=S_{1} \dot{S}_{1} .
$$

Using (20) and (25), the dynamics of the Lyapunov function are written as:

$$
\dot{v}_{1}=-\frac{x_{6}}{C_{\mathrm{pv}} L_{0}} S_{1} u_{0 N}
$$

One seeks $u_{0 N}$ of the type

$$
u_{0 N}=\frac{C_{\mathrm{pv}} L_{0}}{x_{6}} \zeta \operatorname{sgn}\left(S_{1}\right) .
$$

This choice guaranties the negativity of the dynamics of Lyapunov function:

$$
\dot{v}_{1}=-\zeta\left|S_{1}\right|
$$

where $\zeta$ is positive parameter. The final control law is given by

$$
\begin{aligned}
u_{0} & =\frac{1}{x_{6}}\left(L_{0} \dot{i}_{\mathrm{pv}}-\widehat{x}_{4}+r_{0} \widehat{x}_{5}+x_{6}-\varsigma_{21} L_{0} \widetilde{X}_{2}\right. \\
& \left.+L_{0} C_{\mathrm{pv}}\left(\delta \dot{x}_{4}-\ddot{x}_{4}^{*}-\delta \dot{x}_{4}^{*}\right)\right)+\frac{C_{\mathrm{pv}} L_{0} \zeta}{x_{6}} \operatorname{sgn}\left(S_{1}\right) .
\end{aligned}
$$

Proposition 2. Consider the closed-loop control system, consisting of system (6b) in closed loop with the control law (31) and the state adaptive observer error (17). Its dynamic behaviour, expressed in $\left(S_{1}, e_{1}, \widetilde{X}_{2}\right)$-coordinates, is governed by the following equations:

$$
\begin{aligned}
\dot{S} & =-\lambda \operatorname{sgn}\left(S_{1}\right) \\
\dot{e}_{1} & =S_{1}-\delta e_{1} \\
\dot{\widetilde{X}}_{2} & =\left(A_{2}\left(u_{0}\right)-P_{X_{2}}^{-1} C_{2}^{T} C_{2}\right) \widetilde{X}_{2} .
\end{aligned}
$$

System (32) is globally asymptotically stable with respect to the Lyapunov functions (18) and (26). 
3.2.2. Control of Single-Phase Inverter. To guarantee high performance transmission of the power and good functioning of the system, the current and voltage grid should be in phase. Hence, there is a necessity for regulator that enforces the estimate current $\widehat{x}_{1}$ to track a given reference current $\widehat{x}_{1}^{*}=$ $\beta \widehat{x}_{1 r} / \widehat{\theta}_{2}$, where $\beta$ is computed from the output of the outer loop voltage. The proposed controller uses a cascaded loop: an outer voltage loop and an inner current loop. The former compares the sensing DC bus voltage in the link capacitor with the given reference, whereas the latter uses slidingmode controller to regulate the grid current allowing the synchronization of the currents $i_{g}$ with utility grid voltages $v_{g}$.

(i) Network Voltage and Impedance Observer. It is readily checked that equations ( $3 a$ ) and (5a)-(5b) could be given the following compact form:

$$
\begin{aligned}
& \dot{x}_{r}=A_{r} x_{r}+\varphi\left(y_{r}, t\right) \theta \\
& y_{r}=C_{r} x_{r}
\end{aligned}
$$

with

$$
\begin{aligned}
A_{r} & =\left(\begin{array}{ccc}
0 & -1 & 0 \\
0 & 0 & 1 \\
0 & -\omega_{r} & 0
\end{array}\right), \\
x_{r} & =\left(\begin{array}{l}
x_{1} \\
x_{1 r} \\
x_{2 r}
\end{array}\right), \\
\varphi\left(y_{r}\right) & =\left(\begin{array}{cc}
-y_{r} & x_{2} \\
0 & 0 \\
0 & 0
\end{array}\right), \\
C_{r}^{T} & =\left(\begin{array}{c}
1 \\
0 \\
0
\end{array}\right), \\
\theta & =\left(\begin{array}{l}
\theta_{1} \\
\theta_{2}
\end{array}\right) .
\end{aligned}
$$

Then, (33) suggests the following state observer [19] for the estimation of the inaccessible state vector $x_{r}$ and the unknown parameter vector $\theta$ :

$$
\begin{aligned}
\dot{\hat{x}}_{r}= & A_{r} \widehat{x}_{r}+\varphi\left(y_{r}\right) \hat{\theta} \\
& +\left(\Lambda S_{\theta}^{-1} \Lambda^{T} C_{r}^{T}+S_{r}^{-1} C_{r}^{T}\right)\left(y_{r}-C_{r} \widehat{x}_{r}\right) \\
\dot{\hat{\theta}}= & S_{\theta}^{-1} \Lambda^{T} C_{r}^{T}\left(y_{r}-C_{r} \widehat{x}_{r}\right) \\
\dot{\Lambda}= & \left(A_{r}-S_{r}^{-1} C_{r}^{T} C_{r}\right) \Lambda+\Phi\left(y_{r}, t\right) \\
\dot{S}_{r}= & -\rho_{r} S_{r}-A_{r}^{T} S_{r}-S_{r} A_{r}+C_{r}^{T} C_{r} \\
\dot{S}_{\theta}= & -\rho_{\theta} S_{\theta}+\Lambda^{T} C_{r}^{T} C_{r} \Lambda .
\end{aligned}
$$

The notation $\hat{x}_{r} \in \mathbb{R}^{3}$ and $\hat{\theta} \in \mathbb{R}^{2}$, respectively, denote the estimate of the state variables $x_{r}$ and the estimate of the unknown parameters $\theta . S_{r}$ and $S_{\theta}$ are symmetric positive definite matrices with $S_{r}(0)>0$ and $S_{\theta}(0)>0$. Furthermore, $\rho_{r}$ and $\rho_{\theta}$ are positive constants that ensure the rapid convergence of the observers. The $\Lambda$ dynamic is an auxiliary system that can be seen as filter.

The convergence properties of the adaptive observer are analyzed based on the following error system dynamics:

$$
\begin{aligned}
\dot{\tilde{x}}_{r}= & {\left[A_{r}-\left(\Lambda S_{\theta}^{-1} \Lambda^{T} C_{r}^{T} C+S_{r}^{-1} C_{r}^{T} C\right)\right] \tilde{x}_{r} } \\
& +\varphi\left(y_{r}, t\right) \tilde{\theta} \\
\dot{\tilde{\theta}}= & -S_{\theta}^{-1} \Lambda^{T} C_{r}^{T} \tilde{x}
\end{aligned}
$$

with the errors $z_{r}=\tilde{x}_{r}-\Lambda \widetilde{\theta}, \tilde{\theta}=\theta-\widehat{\theta}$, and $\tilde{x}_{r}=x_{r}-\widehat{x}_{r}$, and, following the same idea as in [19], we indeed get

$$
\begin{aligned}
& \dot{z}_{r}=m\left(A_{r}-S_{r}^{-1} C_{r}^{T} C_{r}\right) z_{r} \\
& \dot{\tilde{\theta}}=-\rho_{\theta} S_{\theta}^{-1} \Lambda^{T} C_{r}^{T} C_{r}\left(z_{r}+\Lambda \widetilde{\theta}\right) .
\end{aligned}
$$

One can choose the Lyapunov function (38), to analyze the convergence properties of the observers (35a)-(35e):

$$
L_{f}=z_{r}^{T} S_{r} z_{r}+\widetilde{\theta}^{T} S_{\theta} \widetilde{\theta}
$$

Its time derivation leads to the following inequality:

$$
\begin{aligned}
\dot{L}_{f}\left(z_{r}, \widetilde{\theta}\right)= & -\rho_{X_{j}} z_{r}^{T} S_{r} z_{r}-\rho_{\theta_{j}} \widetilde{\theta}^{T} S_{\theta} \widetilde{\theta} \\
& -\left(z_{r}+\Lambda \widetilde{\theta}\right)^{T}\left(C^{T} C\right)\left(z_{r}+\Lambda_{j} \tilde{\theta}\right)
\end{aligned}
$$

knowing that

$$
-\left(z_{r}+\Lambda \widetilde{\theta}\right)^{T}\left(C^{T} C\right)\left(z_{r}+\Lambda_{j} \tilde{\theta}\right) \leq 0
$$

and this implies that

$$
\dot{L}_{f} \leq-\rho_{\min } L_{f}
$$

with $\rho_{\min }=\min \left(\rho_{r}, \rho_{\theta}\right)$.

The stability results are summarized in the proof which can be found in [11]. Therefore, the error system is exponentially stable with a rate driven by $\rho_{\min }$.

(ii) Power Factor Correction (Inner Current Loop). We seek a law control of sliding-mode type. For the PV system connected to the single-phase grid represented by the average model of (3a)-(3c) and (5a), the sliding-mode control which ensures that the error $e_{2}\left(x_{1}\right)$ tends asymptotically to zero in finite time can be written as follows:

$$
u_{1}=u_{1 \mathrm{eq}}+u_{1 \mathrm{dis}}
$$

To design this controller, one defines the sliding surface:

$$
S_{2}(x)=\left(\frac{d}{d t}+\lambda\right)^{n-1} e_{2}\left(x_{1}\right),
$$


where $n=3$ is the relative degree of the system, and $e_{2}\left(\widehat{x}_{1}\right)=$ $\widehat{x}_{1}-x_{1}^{*}$ is the error between the signal and its reference $x_{1}^{*}$. The surface is given by

$$
\begin{aligned}
S_{2}\left(\widehat{x}_{1}\right)= & -\dot{\hat{\theta}}_{1} \widehat{x}_{1}-\widehat{\theta}_{1} \dot{\hat{x}}_{1}-\dot{\hat{x}}_{1 r}+\dot{\hat{\theta}}_{2} \widehat{x}_{2}+\widehat{\theta}_{2} \dot{\hat{x}}_{2}+2 \lambda \dot{\hat{x}}_{1} \\
& +\lambda^{2} \widehat{x}_{1}-\ddot{x}_{1}^{*}-2 \lambda \dot{x}_{1}^{*}-\lambda^{2} x_{1}^{*} .
\end{aligned}
$$

Consider the first derivative of

$$
\begin{aligned}
\dot{S}_{2}\left(\widehat{x}_{1}\right)= & -\ddot{\hat{\theta}}_{1} \widehat{x}_{1}+\left(\lambda^{2}-2 \dot{\hat{\theta}}_{1}\right) \dot{\hat{x}}_{1}+\left(2 \lambda-\widehat{\theta}_{1}\right) \ddot{\tilde{x}}_{1} \\
& -\ddot{\ddot{x}}_{1 r}+\ddot{\hat{\theta}}_{2} \widehat{x}_{2}+\dot{\hat{\theta}}_{2} \dot{\hat{x}}_{2}+\frac{\widehat{\theta}_{2}}{C} u_{1} x_{6}-\frac{1}{C} \dot{\hat{\theta}}_{2} \widehat{x}_{1} \\
& +\frac{1}{C} \dot{\hat{\theta}}_{2} \widehat{x}_{3} \\
& +\widehat{\theta}_{2}\left(-\frac{1}{C L_{2}} \widehat{x}_{2}-\frac{r_{2}}{C L_{2}} \widehat{x}_{3}+\frac{1}{C} \eta_{13} \widetilde{x}_{1}\right) \\
& +\dot{\eta}_{12} \widehat{\theta}_{2} \widetilde{x}_{1}-\frac{1}{C} \widehat{\theta}_{2} \dot{\hat{x}}_{1}+\eta_{12} \dot{\hat{\theta}}_{2} \widetilde{x}_{1}+\eta_{12} \widehat{\theta}_{2} \dot{\tilde{x}}_{1} \\
& -\dot{x}_{1}^{*}-2 \lambda \ddot{x}_{1}^{*}-\lambda^{2} \dot{x}_{1}^{*} .
\end{aligned}
$$

The command $u_{1}$ appears in the first derivative of the sliding surface. Then the equivalent command $u_{1 \text { eq }}=u_{1}$ is deduced from of invariance of the surface $S_{2}\left(\widehat{x}_{1}\right)=\dot{S}_{2}\left(\widehat{x}_{1}\right)=0$. One obtained

$$
\begin{aligned}
& u_{1 \mathrm{eq}}=\frac{C}{\widehat{\hat{\theta}}_{2} x_{6}}\left(\ddot{\tilde{\theta}}_{1} \widehat{x}_{1}-\left(\lambda^{2}-2 \dot{\hat{\theta}}_{1}\right) \dot{\hat{x}}_{1}-\left(2 \lambda-\widehat{\theta}_{1}\right) \ddot{\tilde{x}}_{1}\right. \\
& +\ddot{\tilde{x}}_{1 r}-\ddot{\hat{\theta}}_{2} \widehat{x}_{2}-\dot{\hat{\theta}}_{2} \dot{\hat{x}}_{2}+\frac{1}{C} \dot{\hat{\theta}}_{2} \widehat{x}_{1}+\frac{1}{C} \widehat{\theta}_{2} \dot{\hat{x}}_{1}-\frac{1}{C} \dot{\hat{\theta}}_{2} \widehat{x}_{3} \\
& -\widehat{\theta}_{2}\left(-\frac{1}{C L_{2}} \widehat{x}_{2}-\frac{r_{2}}{C L_{2}} \widehat{x}_{3}+\frac{1}{C} \eta_{13} \widetilde{x}_{1}\right)-\dot{\eta}_{12} \widehat{\theta}_{2} \tilde{x}_{1} \\
& \left.-\eta_{12} \dot{\hat{\theta}}_{2} \widetilde{x}_{1}-\eta_{12} \widehat{\theta}_{2} \dot{\tilde{x}}_{1}+\dot{x}_{1}^{*}+2 \lambda \ddot{x}_{1}^{*}+\lambda^{2} \dot{x}_{1}^{*}\right) \text {. }
\end{aligned}
$$

To elaborate the discontinuous control, consider the following Lyapunov function candidate:

$$
w_{1}=\frac{1}{2} S_{2}^{2} .
$$

Its dynamics are given by

$$
\dot{w}_{1}=S_{2} \dot{S}_{2} .
$$

Differentiating $w_{1}$ with respect to time, using (42) and (45), the dynamics of the Lyapunov function are written as

$$
\dot{w}_{1}=\frac{\hat{\theta}_{2}}{C} x_{6} S_{2} u_{1 d s} .
$$

Moreover, (48) shows that, to ensure the stability of the closed-loop system, a choice for $u_{1 d s}$ is of the form

$$
u_{1 d s}=-\frac{\gamma C}{\hat{\theta}_{2} x_{6}} \operatorname{sgn}\left(S_{2}\right) .
$$

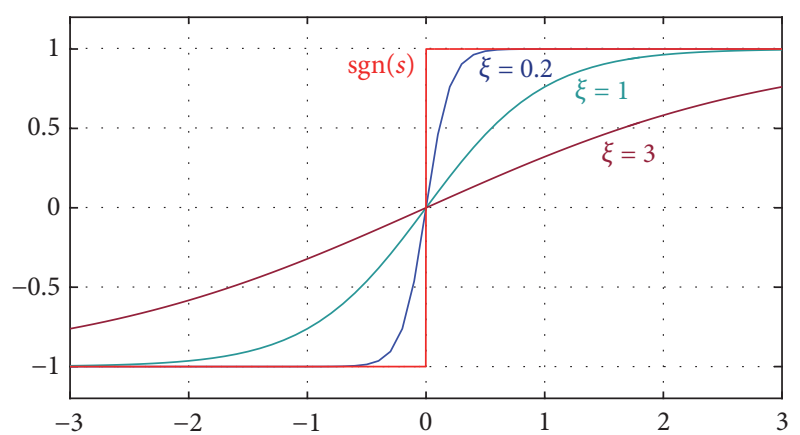

Figure 3: $\operatorname{sgn}(s)$ and $\tanh (s / \xi)$ for $\xi=3,0.2$, and 1 .

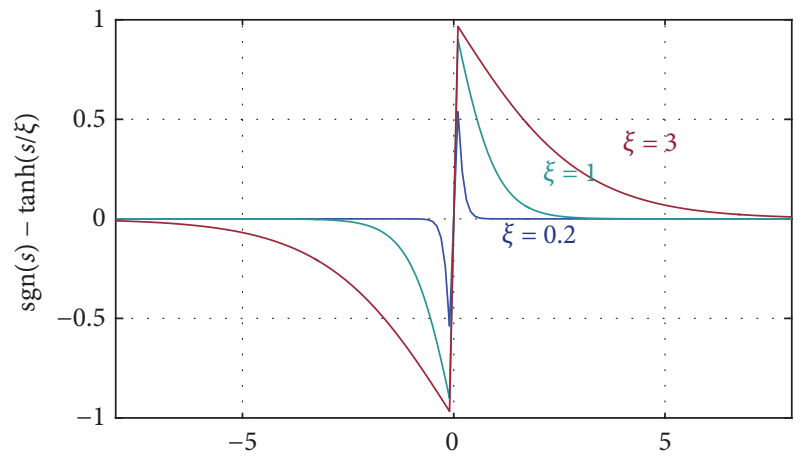

FIGURE 4: Errors between $\operatorname{sgn}(s)$ and $\tanh (s / \xi)$ for $\xi=3,0.2$, and 1 .

The choice of (49) guarantees the negativity of the dynamics of Lyapunov function, so

$$
\dot{w}_{1}=-\gamma\left|S_{2}\right|,
$$

where $\gamma$ is positive parameter and $\operatorname{sgn}(\cdot)$ is the sign function defined as follows:

$$
\operatorname{sgn}\left(S_{2}\right)= \begin{cases}+1 & \text { when } S_{2}\left(x_{1}\right)>0 \\ -1 & \text { when } S_{2}\left(x_{1}\right)<0 .\end{cases}
$$

The overall law is given by

$$
\begin{aligned}
u_{1} & =\frac{C}{\widehat{\theta}_{2} x_{6}}\left(\ddot{\hat{\theta}}_{1} x_{1}-\left(\lambda^{2}-2 \dot{\hat{\theta}}_{1}\right) \dot{\bar{x}}_{1}-\left(2 \lambda-\widehat{\theta}_{1}\right) \ddot{\hat{x}}_{1}\right. \\
& +\ddot{\tilde{x}}_{1 r}-\ddot{\hat{\theta}}_{2} \widehat{x}_{2}-\dot{\hat{\theta}}_{2} \dot{\bar{x}}_{2}+\frac{1}{C} \dot{\hat{\theta}}_{2} \widehat{x}_{1}+\frac{1}{C} \widehat{\theta}_{2} \dot{\bar{x}}_{1}-\frac{1}{C} \dot{\hat{\theta}}_{2} \widehat{x}_{3} \\
& -\widehat{\theta}_{2}\left(-\frac{1}{C L_{2}} \widehat{x}_{2}-\frac{r_{2}}{C L_{2}} \widehat{x}_{3}+\frac{1}{C} \eta_{13} \widetilde{x}_{1}\right)-\dot{\eta}_{12} \widehat{\theta}_{2} \widetilde{x}_{1} \\
& -\eta_{12} \dot{\hat{\theta}}_{2} \widetilde{x}_{1}-\eta_{12} \widehat{\theta}_{2} \dot{\tilde{x}}_{1}+\dot{\ddot{x}}_{1}^{*}+2 \lambda \ddot{x}_{1}^{*}+\lambda^{2} \dot{x}_{1}^{*} \\
& \left.-\gamma \operatorname{sgn}\left(S_{2}\right)\right) .
\end{aligned}
$$

In order to minimize the chattering effect generated by the discontinuity of the $\operatorname{sgn}(\cdot)$ function at the point zero, we propose replacing in the previous control laws (31) and (52) this function by the modified function, namely, $\tanh (s / \xi)$ 

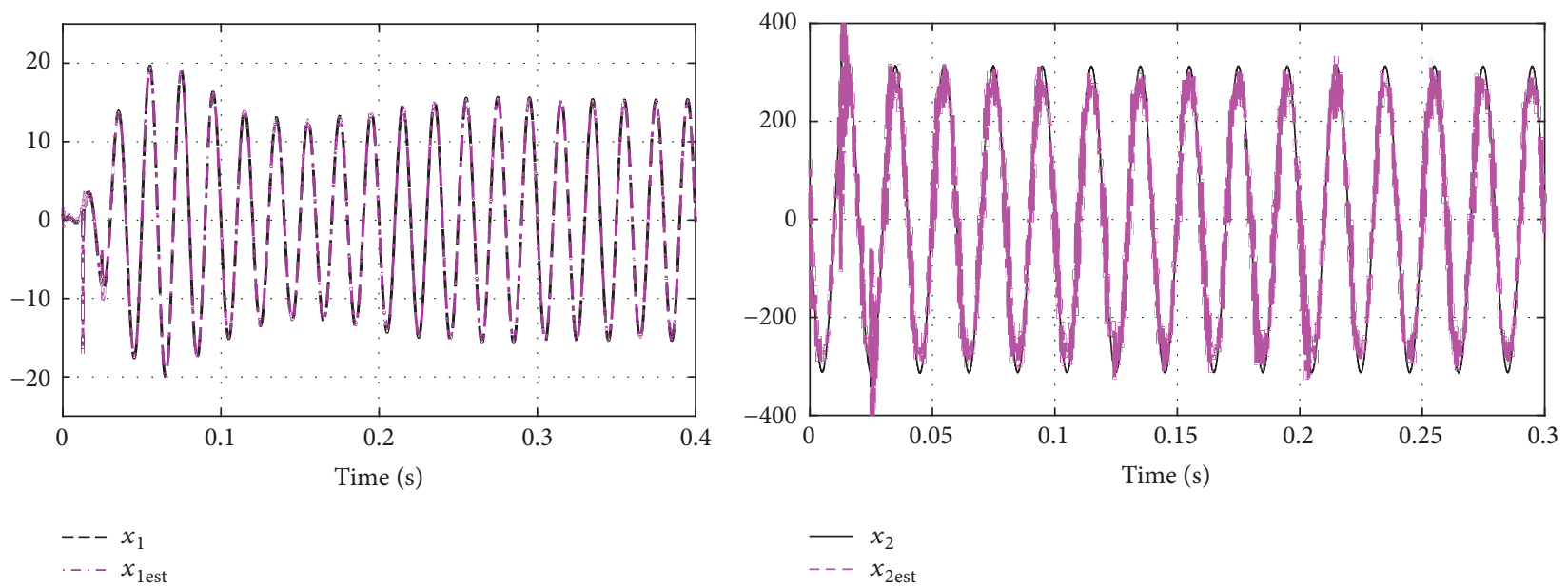

(a)
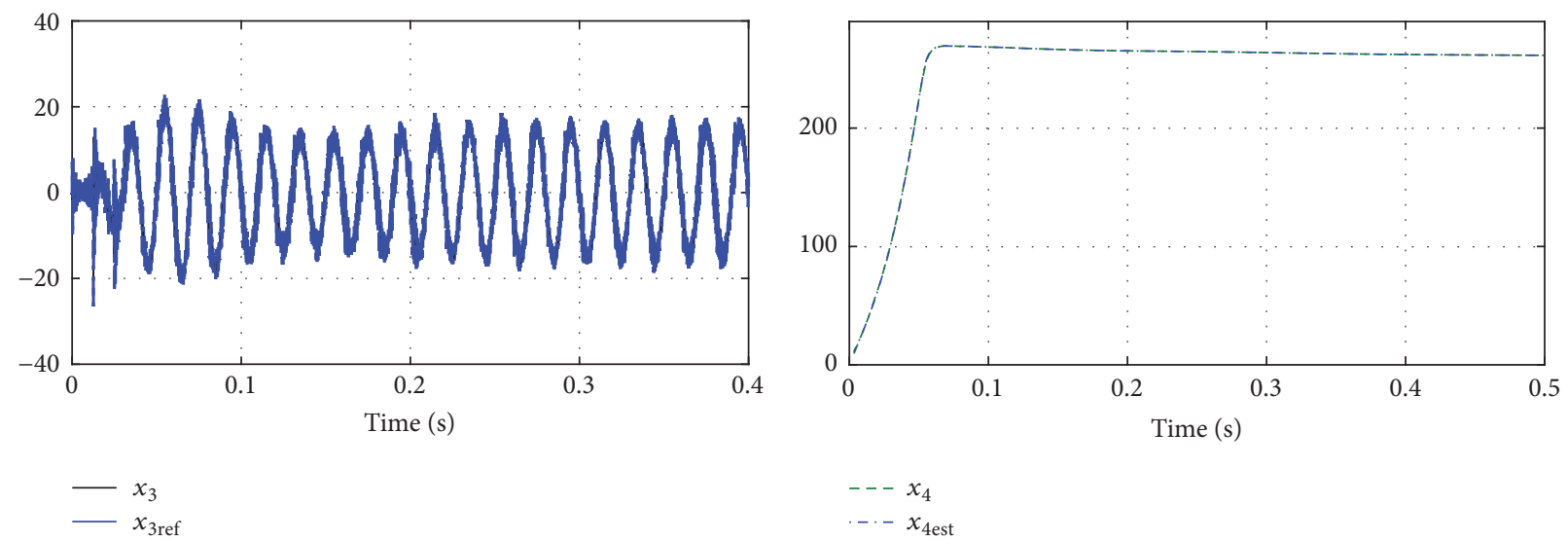

(c)

(d)

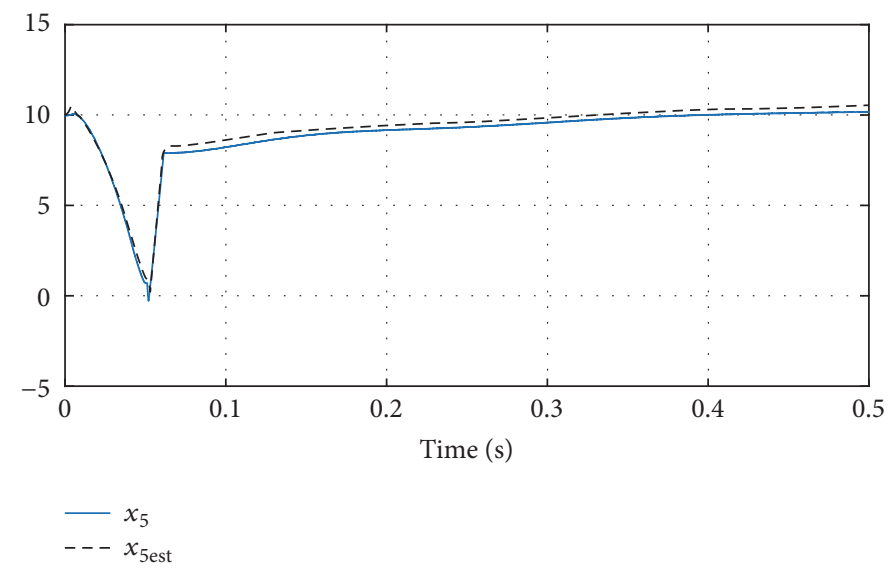

(e)

FIgURE 5: (a) Grid current and its estimate. (b) Capacitor filter voltage and its estimate. (c) Inverter output current and its estimate. (d) PV voltage and its estimate. (e) Current of inductance boost and its estimate.

which is closer to the function $\operatorname{sgn}(\cdot)$ but it is continuous especially at the point zero. The real positive constant $\xi$ is selected sufficiently small to better approach the function $\operatorname{sgn}(\cdot)$.

Figure 3 shows that, for smaller values of $\xi$, the function $\tanh (\cdot)$ behaves close to a function $\operatorname{sgn}(s)$. Figure 4 depicts the errors between $\operatorname{sgn}(s)$ and $\tanh (s / \xi)$, which shows that the error decreases for small values of $\xi$.

(iii) DC Bus Proportional-Integral Control (Outer Voltage Loop). The objective of this loop is to generate the signal $\beta$ so that the square of the DC bus voltage $y=\left(x_{6}\right)^{2}$ is regulated 
TABLE 2: PV system and single-phase grid characteristics.

\begin{tabular}{lcc}
\hline Parameters & Symbol & Value \\
\hline Network & $E_{n} / f$ & $220 \sqrt{2} \mathrm{~V} / 50 \mathrm{~Hz}$ \\
Boost & $C_{\mathrm{pv}}, L_{0}, r_{0}$ & $2 \mathrm{mF}, 0.3 \mathrm{mH}, 5 \mathrm{~m} \Omega$ \\
LCL-filter & $L_{1}, r_{1}, C, L_{2}, r_{2}$ & $2 \mathrm{mH}, 5 \mathrm{~m} \Omega, 5 \mu \mathrm{F}, 2 \mathrm{mH}, 5 \mathrm{~m} \Omega$ \\
PWM switching & $f_{\mathrm{PWM}}$ & $14 \mathrm{Khz}$ \\
frequency & $C_{\mathrm{dc}}$ & $4 \mathrm{mF}$ \\
DC capacitance & & \\
\hline
\end{tabular}

to a reference value $y^{*}=\left(x_{6}^{*}\right)^{2}$. Considering the fact that $\beta$ and its time derivatives should be available, a filtered control law of type PI is retained; namely,

$$
\beta=\left(\frac{c_{3}}{c_{3}+s}\right)^{3}\left(k_{p} z_{1}+k_{i} z_{2}\right)
$$

with

$$
\begin{aligned}
& z_{1}=y^{*}-y, \\
& z_{2}=\int_{0}^{t} z_{1} d \tau,
\end{aligned}
$$

where " $s$ " denotes the Laplace variable and $\left(c_{3}, k_{p}, k_{i}\right)$ are any positive real constants.

\section{Simulation}

In this section, the controller that has been designed in the above section using output nonlinear feedback technique will be tested. The simulation results have been obtained under normal conditions $\left(G=1000 \mathrm{w} / \mathrm{m}^{2} ; T=25^{\circ} \mathrm{C}\right)$ and other different conditions. The whole system (power system and controllers) is simulated with the numerical values of Tables 2 and 3. The parameters of the controllers are determined based on the desired specifications of the closed-loop system. In this paper, the controller parameters are designed so that the current control loop has much faster response than that of the DC-link voltage control loop. In this work the value $\xi=0.1$ is used.

4.1. Tracking Performance in the Presence of Meteorological Constant. Figures 5-17 show the results of simulation, which are selected to demonstrate the most significant aspects of the PV system grid-connected behaviour. Figure 5 shows that the observers do well. Also, Figures 5(a)-5(e) show that the estimated state provided by the observers converges rapidly due to its true values.

Figure 6 shows the grid current spectrogram, where the THD value of this current is very low equal to $1.37 \%$, which is still below the international standards. The performances of the grid adaptive observer are illustrated by Figures 7-10. Indeed in Figures 7 and 8 it is observed that the estimated parameters $\widehat{\theta}_{1}$ and $\hat{\theta}_{2}$, provided by the grid adaptive observer, converge rapidly to their true values, respectively, $\left(r_{1}+\right.$ $\left.r_{g}\right) /\left(L_{1}+L_{g}\right)$ and $1 /\left(L_{1}+L_{g}\right)$ after a short transient phase. Figures 9 and 10 show that the estimated signals of the grid
TABLE 3: Controller parameters.

\begin{tabular}{lcc}
\hline & Parameters & Value \\
\hline \multirow{3}{*}{ Luenberger observer } & $m_{1}$ & 6399 \\
& $m_{2}$ & 6166 \\
& $m_{3}$ & 1776 \\
\hline Current regulator (PFC) & $\lambda, \gamma$ & 4500,40 \\
\hline Voltage regulator & $\delta, \zeta$ & $44.16,19.6$ \\
\hline \multirow{2}{*}{ DC Link regulator } & $k_{p}$ & $88.4 e-8$ \\
& $k_{i}$ & $695.8 e-8$ \\
\hline
\end{tabular}

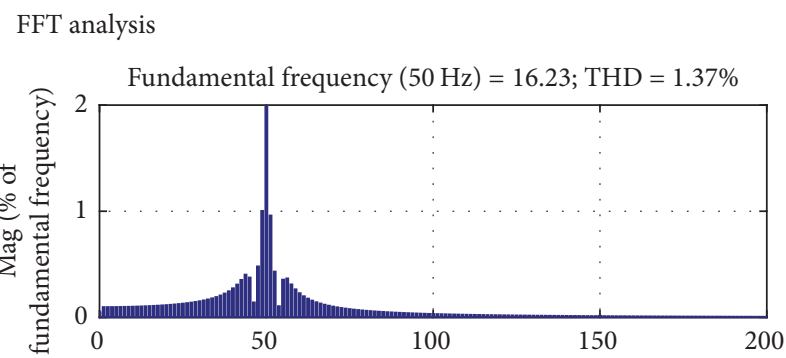

FIGURE 6: FFT analysis of grid current.

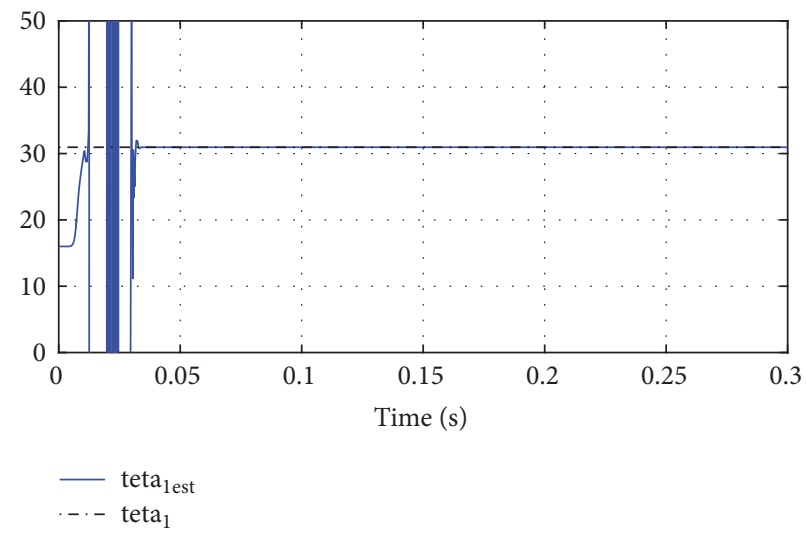

Figure 7: Unknown parameter $\theta_{1}$ and its estimated $\widehat{\theta}_{1}$.

current $\widehat{x}_{1}$ and of the grid voltages $\widehat{v}_{g}=\widehat{x}_{1 r} / \widehat{\theta}_{2}$ converge, respectively, to their true values $x_{1}$ and $v_{g}=x_{1 r} / \theta_{2}$.

Figure 11 illustrates the response of the PV voltage in standard climatic conditions. It can be clearly seen that, in steady state, the PV generator provides the maximal power, which is equal to $250 \mathrm{~V}$. Figure 12 presents a view of the injected current in the grid with its reference; as it is seen in the figure that the current follows its reference with error nearly 0 . Figure 13 shows the regulation of the DC-link voltage. As shown in the figure, the voltage is maintained at a constant level $(650 \mathrm{~V})$. Consequently, the real power extracted from the PV generator can be totally transferred to the grid. In the last figure, Figure 14 shows the current injected to the grid. As can be seen in this figure, the current and the grid voltage are in phase and sinusoidal. As a result, a unit power factor is achieved.

Different powers of the system are given by Figures 15-17. Figure 15 shows the power provided by the PV generators. 


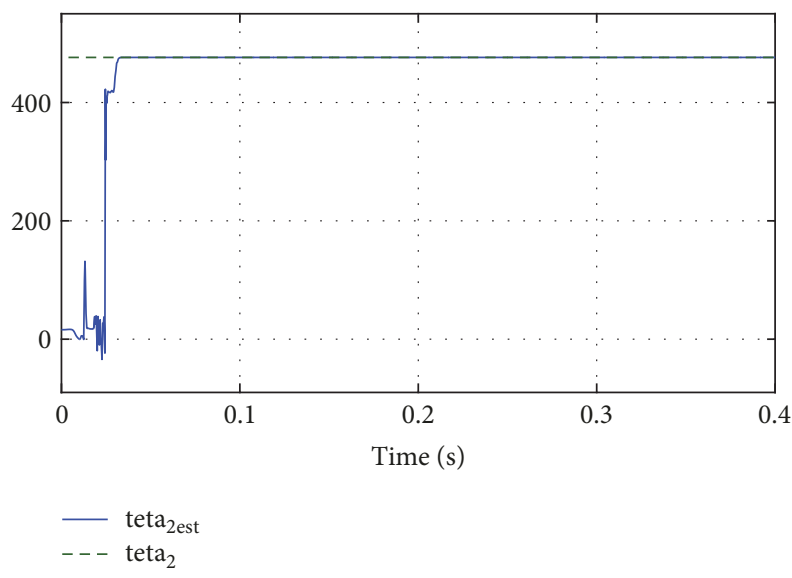

Figure 8: Unknown parameter $\theta_{2}$ and its estimated $\widehat{\theta}_{2}$.

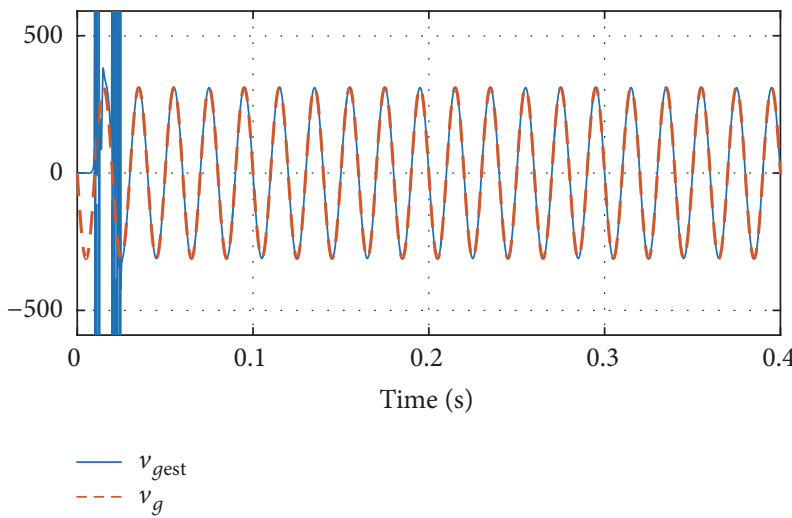

FIGURE 9: Grid voltage $v_{g}=x_{1 r} / \theta_{2}$ and its estimated $\widehat{v}_{g}=\widehat{x}_{1 r} / \widehat{\theta}_{2}$.

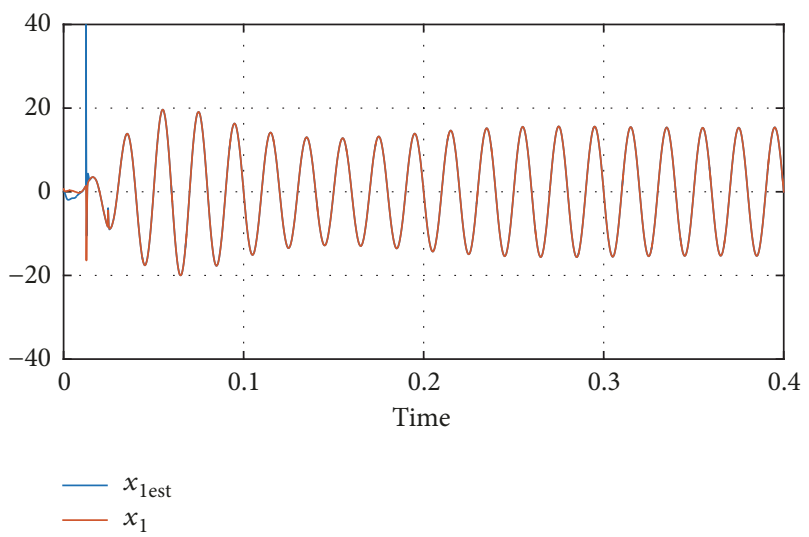

Figure 10: Grid current $x_{1}$ and its estimated $\widehat{x}_{1}$.

According to Figures 16 and 17, the system injects into the grid active power $P_{\text {grid }}$, where the reactive power $Q_{\text {grid }}$ is kept around zero.

4.2. Tracking Performance in the Presence of Meteorological Variation. The robustness of the nonlinear adaptive controller is checked under a time variation climate conditions. The purpose of this simulation is to test the closed-loop

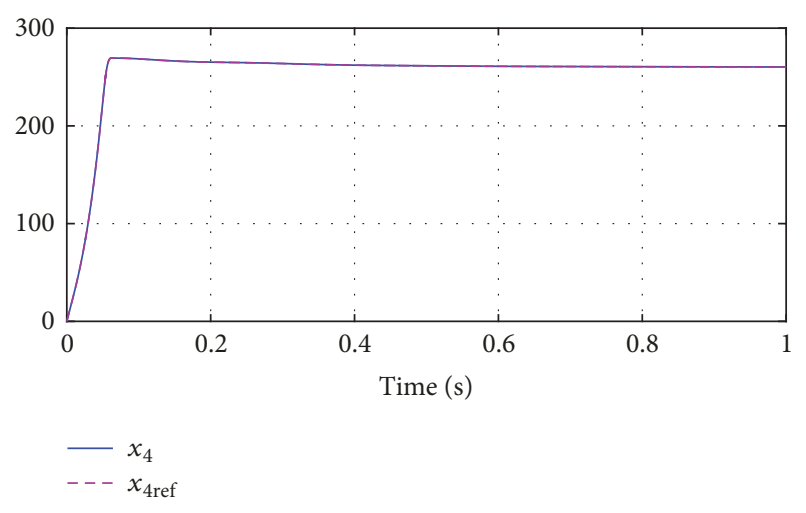

Figure 11: PV voltage and its reference.

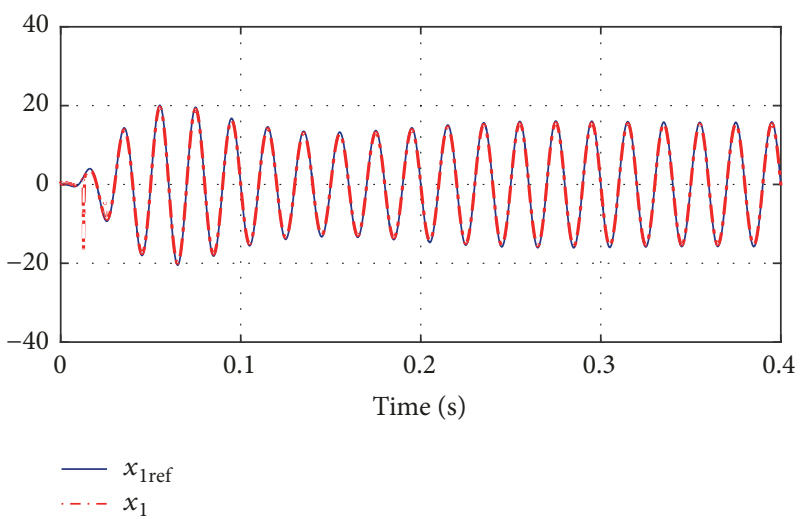

FIGURE 12: Injected current and its reference.

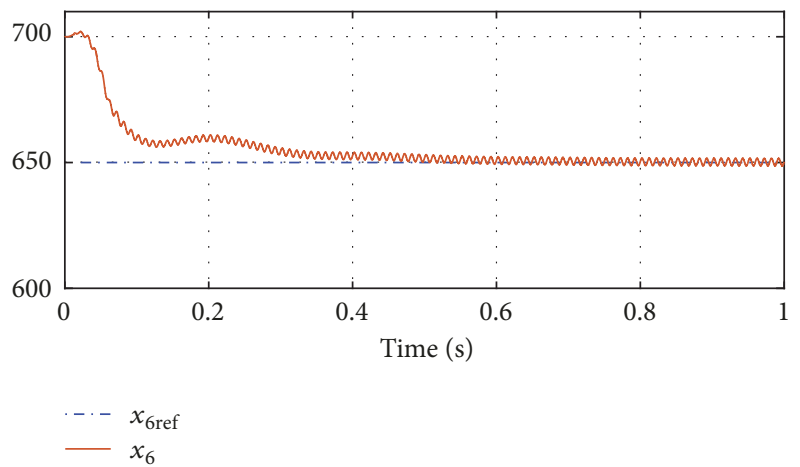

FIGURE 13: DC bus voltage.

system under a change in the PV output that occurred by a sudden change in climate change. In the following simulations, the DC-link capacitor voltage is kept constant equal to $650 \mathrm{~V}$.

The levels of the irradiance are illustrated in Figure 18, which shows that the irradiation has increased from $900 \mathrm{~W} / \mathrm{m}^{2}$ to $1000 \mathrm{~W} / \mathrm{m}^{2}$ at $0.3 \mathrm{~s}$.

In the following simulations, the output-feedback controller performances are illustrated by Figure 19. The curves $(\mathrm{a}-\mathrm{c})$ show that the tracking quality of the proposed observers is quite satisfactory for all supposed unknown states. Figure 19(b) shows that, despite the sudden large change in 


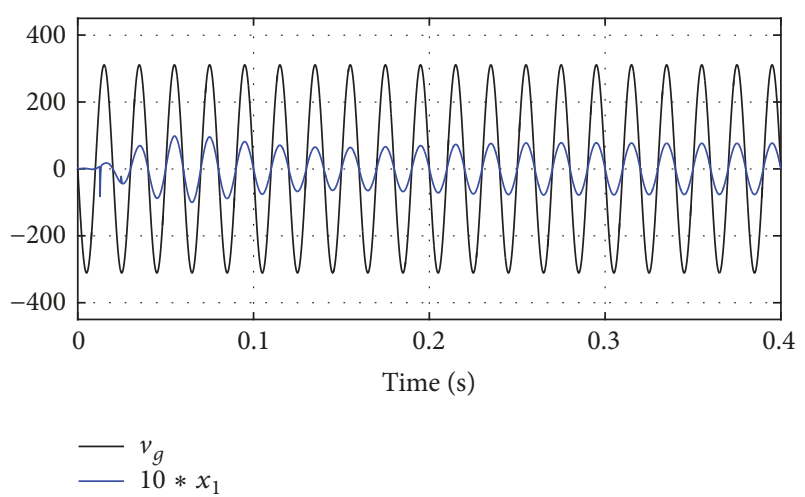

FIgURE 14: PFC checking.

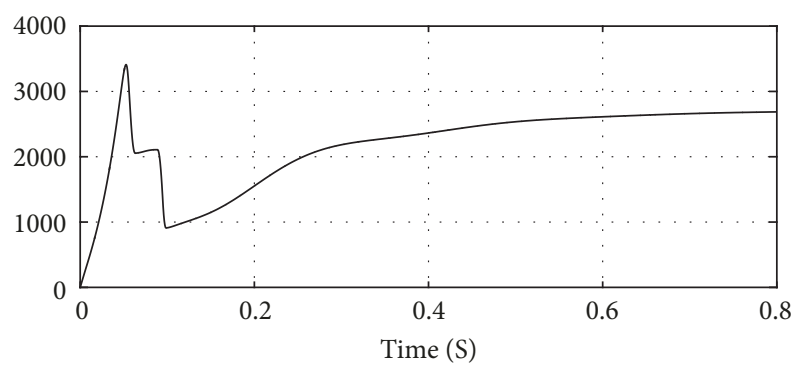

Figure 15: PV power.

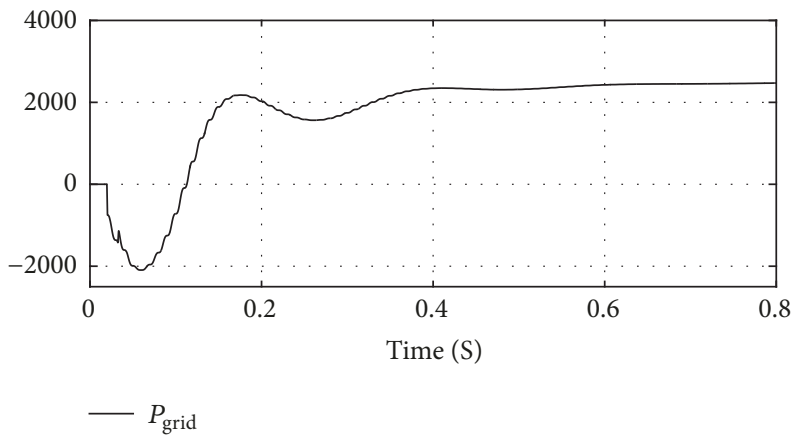

FIGURE 16: Active grid power.

irradiance, the inner loop ensures a perfect asymptotic tracking of the current reference signal. Figure 19(c) shows that the DC bus voltage regulation is recovered after a short transient period following each change of the irradiation. Finally, Figure 19(d) shows that the correction of the power factor is preserved even during variations of irradiation.

4.3. The Controller's Ability to Compensate for Variation in Network Impedance Parameters. The aim of this test is to check the grid current controller performance in the presence of variations in the network impedance. The elements of the impedances $\left(L_{q}\right)$ and $\left(R_{g}\right)$ are modified, according to the protocol presented in Figure 20, to generate variations at $\theta_{1}$ and $\theta_{2}$. Note that all system parameters are those used for previous tests.

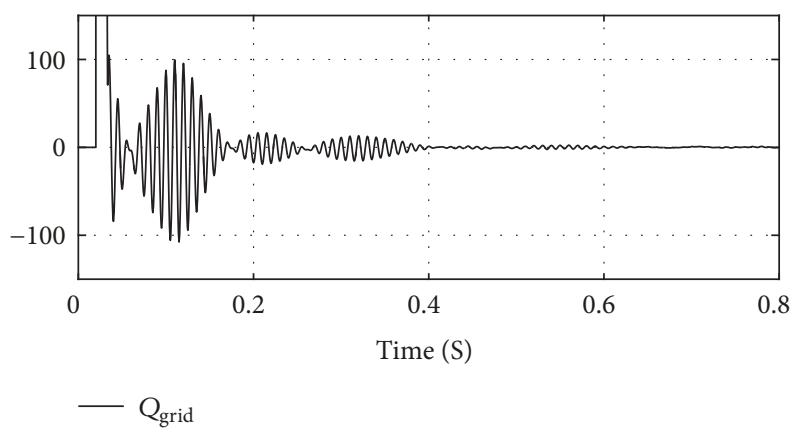

FIgURE 17: Reactive grid power.

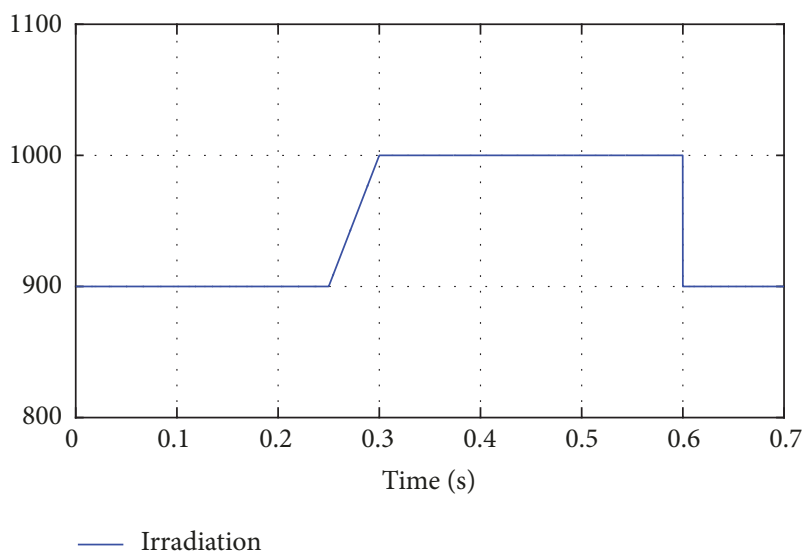

FIGURE 18: Irradiance variations.

The following figures present the simulation results in the case of variations undergone by the network impedance. Figures 21 and 22 show that unknown parameters and network current estimates converge rapidly to their actual trajectories. Finally, Figure 23 illustrates that the adaptive controller provides satisfactory power factor correction during the uncertainty interval.

4.4. Tracking Performance in the Presence of Grid Faults. This test aims at evaluating the performance of the system against the change of the amplitude and the frequency of the grid. The amplitude and the reference of the grid are modified according to the protocol presented in Figure 24.

Figures 25 and 26 show that, in spite of the variation of the amplitude and the frequency of the grid, the regulator has the capacity to track the reference provided by the outer loop and to inject a current in phase with the grid voltage.

Note that, for all simulations, it is clear that the proposed controller reacts in a quick manner to reach the reference and to remove the steady-state error quickly to keep the stability of the system.

\section{Conclusion}

An output-feedback nonlinear control strategy for a singlephase grid-connected PV system is proposed in this paper. The system is described by 6th order nonlinear averaged 

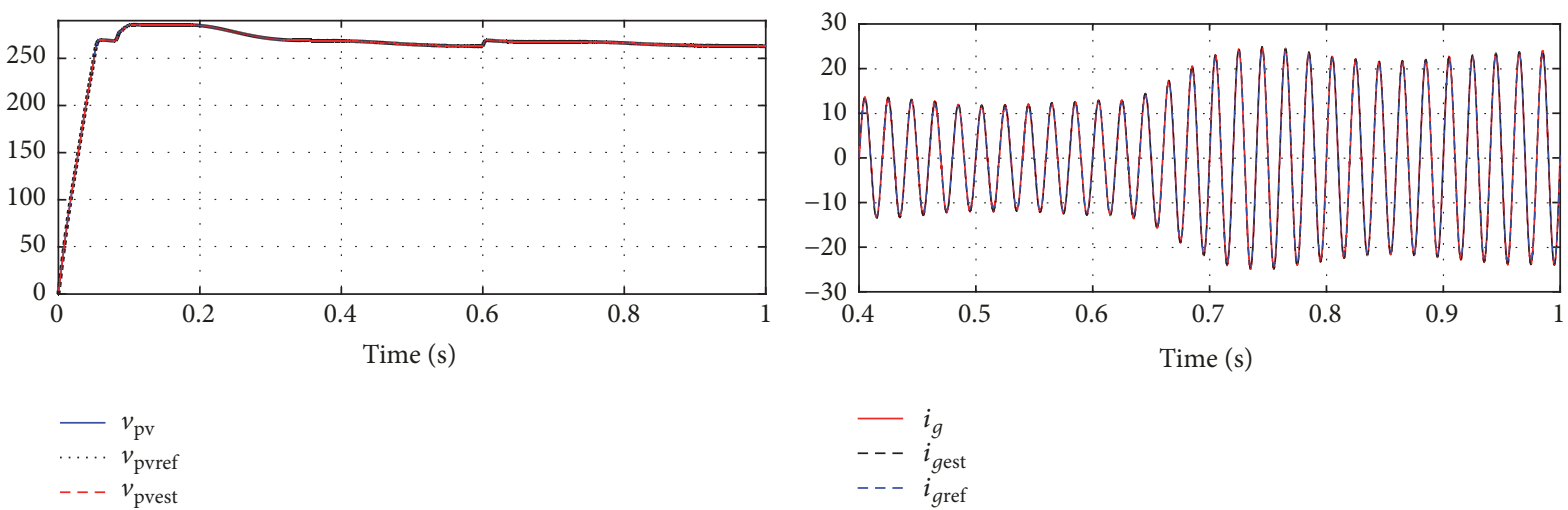

(a)

(b)
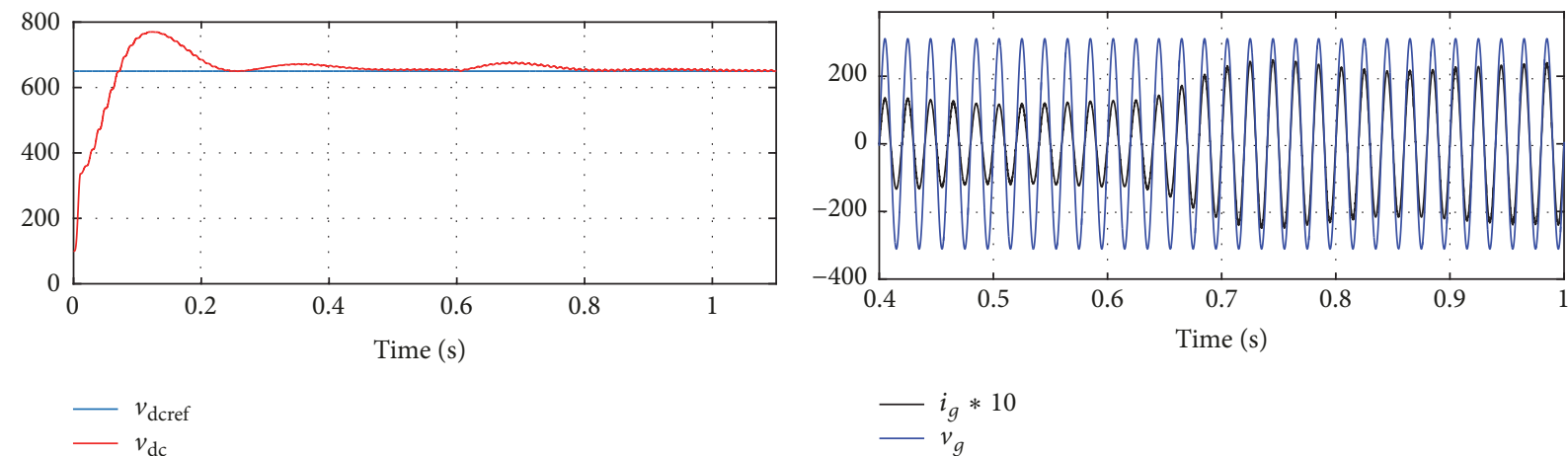

(c)

(d)

FIGURE 19: Tracking performances of controllers. (a) PV voltage. (b) Grid current. (c) DC-link capacitor voltage. (d) Voltage and grid current.

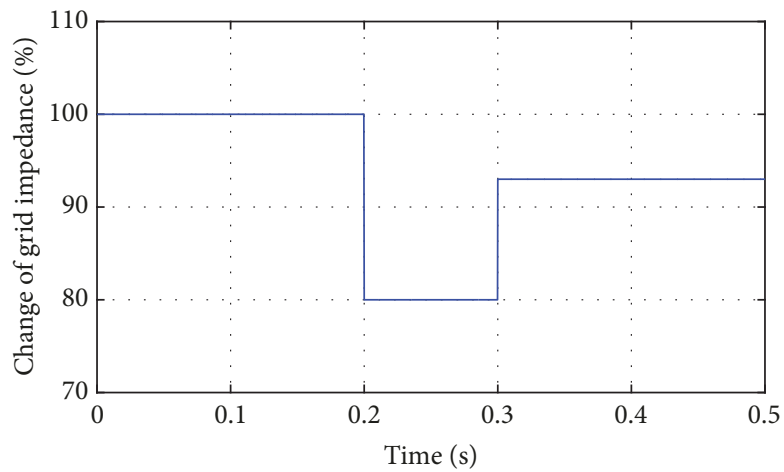

FIGURE 20: Grid impedance variation.
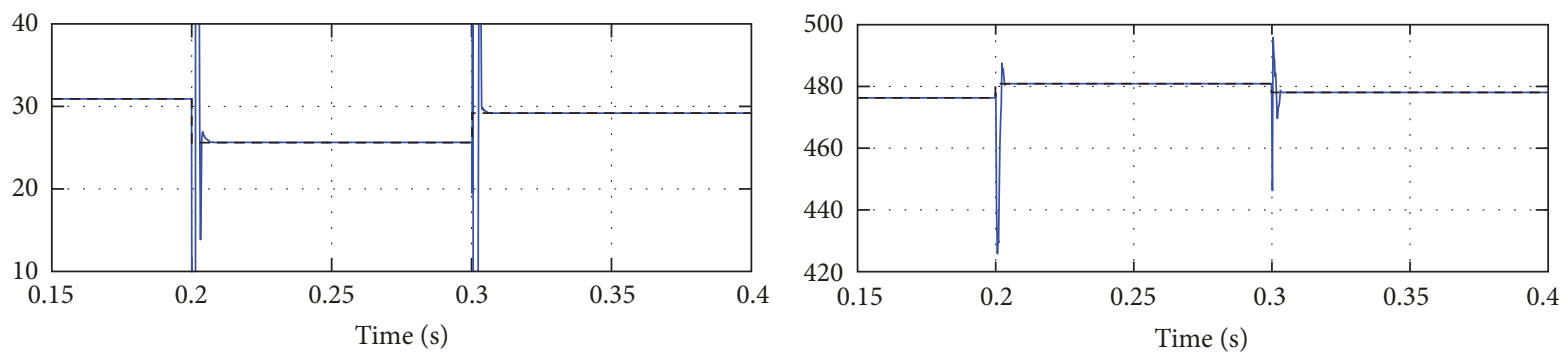

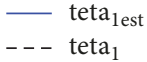

(a) The parameter $\theta_{1}$ and its estimate $\widehat{\theta}_{1}$
- teta ${ }_{2 \text { est }}$

- - - teta 2

(b) The parameter $\theta_{2}$ and its estimate $\widehat{\theta}_{2}$

Figure 21 


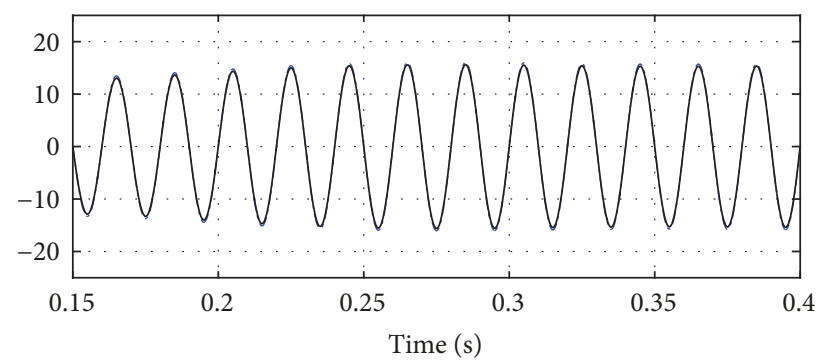

$-\cdot-x_{1 \text { ref }}$

$-x_{\text {lest }}$

FIGURE 22: Grid current and its estimate.

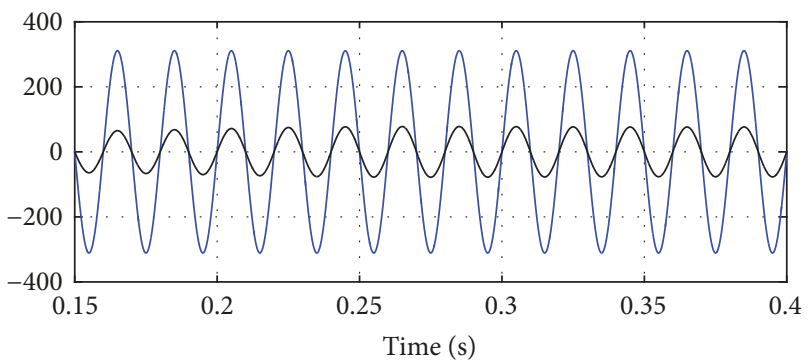

$-v_{g}$

FIGURE 23: PFC checking.

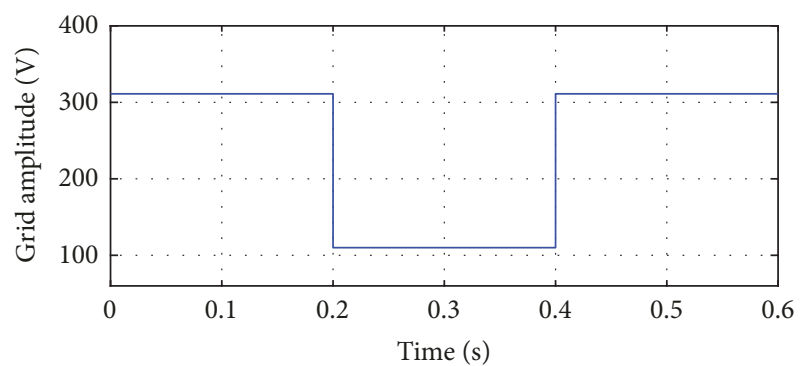

(a) Grid amplitude

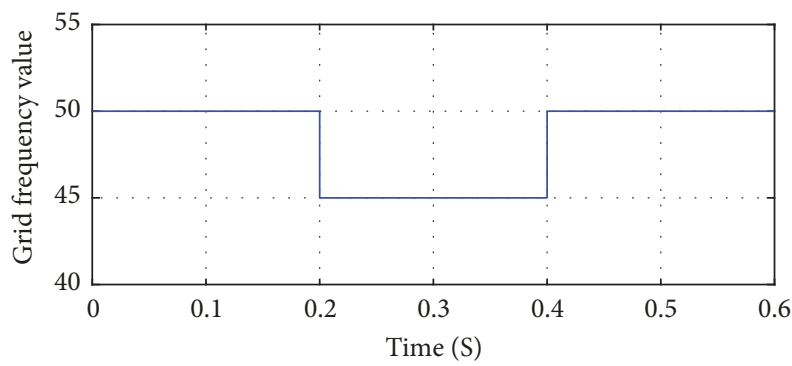

(b) Grid frequency

Figure 24

model. The controller design is made based on a combination of robust sliding-mode control strategy and nonlinear observers. The simulations under MATLAB/Simulink prove that the controller meets the performance for which it was

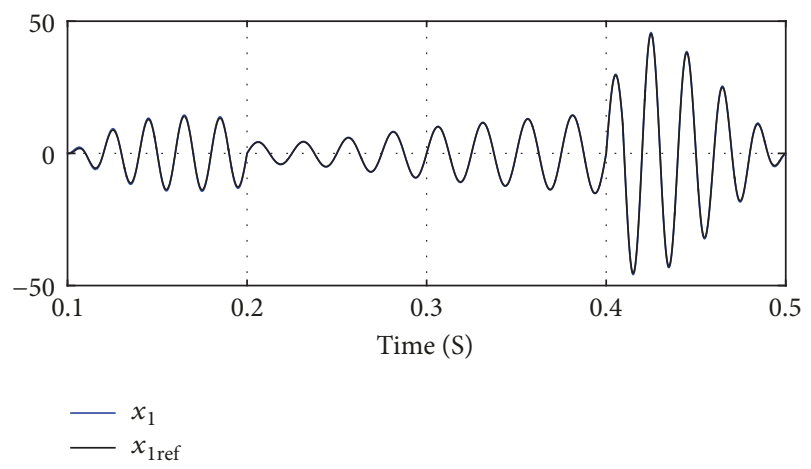

FIGURE 25: Reference tracking.

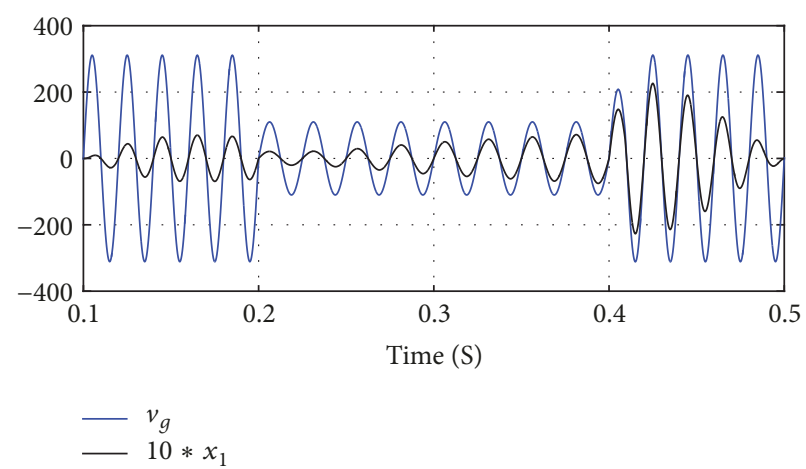

FIGURE 26: PFC checking under grid faults.

designed. Specifically, it is shown that all control objectives are achieved, including PFC requirement, extracting a maximum power from the PV array and DC-link voltage regulation without requiring a lot of current and voltage sensors.

\section{Conflicts of Interest}

The authors declare that there are no conflicts of interest regarding the publication of this paper.

\section{References}

[1] T. Ackermann, Ed., Wind Power in Power Systems, John Wiley \& Sons, Chichester, UK, 2005.

[2] S. Dasgupta, S. K. Sahoo, and S. K. Panda, "A new control strategy for single phase series connected PV module inverter for grid voltage compensation," in Proceedings of the 2009 International Conference on Power Electronics and Drive Systems, PEDS 2009, pp. 1317-1322, Taiwan, January 2009.

[3] M. Ciobotaru, R. Teodorescu, and F. Blaabjerg, "Control of Single-Stage Single-Phase PV Inverter," EPE Journal, vol. 16, no. 3, pp. 20-26, 2015.

[4] A. Tofighi and M. Kalantar, "Power management of PV/battery hybrid power source via passivity-based control," Journal of Renewable Energy, vol. 36, no. 9, pp. 2440-2450, 2011.

[5] I. Sefa, N. Altin, S. Ozdemir, and O. Kaplan, "Fuzzy PI controlled inverter for grid interactive renewable energy systems," IET Renewable Power Generation, vol. 9, no. 7, pp. 729-738, 2015. 
[6] R. Benadli, B. Khiari, and A. Sellami, "Three-phase gridconnected photovoltaic system with maximum power point tracking technique based on voltage-oriented control and using sliding mode controller," in Proceedings of the 2015 6th International Renewable Energy Congress, IREC 2015, Tunisia, March 2015.

[7] C. Aouadi, A. Abouloifa, I. Lachkar et al., "Multi loop based control of photovoltaic system connected to the single phase grid," in Proceedings of the 2016 International Renewable and Sustainable Energy Conference, IRSEC 2016, pp. 479-486, Morocco, November 2016.

[8] C. Aouadi, A. Abouloifa, A. Hamdoun, and Y. Boussairi, "Nonlinear controller design for single-phase grid-connected photovoltaic systems," in Proceedings of the IEEE International Renewable and Sustainable Energy Conference, IRSEC 2015, Morocco, December 2015.

[9] M. Aourir, A. Abouloifa, I. Lachkar, A. Hamdoun, F. Giri, and F. Cuny, "Nonlinear Control of PV System Connected to Single Phase Grid through Half Bridge Power Inverter," IFACPapersOnLine, vol. 50, no. 1, pp. 741-746, 2017.

[10] C. Aouadi, A. Abouloifa, M. Aourir, Y. Boussairi, A. Hamdoun, and I. Lachkar, "State-feedback nonlinear control of threephase grid connected to the photovoltaic system," in Proceedings of the 17th IEEE International Conference on Environment and Electrical Engineering and 2017 1st IEEE Industrial and Commercial Power Systems Europe, June 2017.

[11] R. Errouissi, A. Al-Durra, and S. M. Muyeen, "Offset-free feedback linearisation control of a three-phase grid-connected photovoltaic system," IET Power Electronics, vol. 9, no. 9, pp. 1933-1942, 2016.

[12] C. Meza, J. J. Negroni, D. Biel, and F. Guinjoan, "Energy-balance modeling and discrete control for single-phase grid-connected PV central inverters," IEEE Transactions on Industrial Electronics, vol. 55, no. 7, pp. 2734-2743, 2008.

[13] J. Hu, J. Zhu, and D. G. Dorrell, "Predictive Control of GridConnected Inverters for PV Systems With Flexible Power Regulation and Switching Frequency Reduction," IEEE Transactions on Industry Applications, vol. 51, no. 1, Article ID 587594, 2015.

[14] M. Karimi-Ghartemani, S. A. Khajehoddin, P. Jain, and A. Bakhshai, "Control of three-phase converters for gridconnected renewable energy systems using feedback linearization technique," in Proceedings of the 2010 IEEE International Symposium on Industrial Electronics, ISIE 2010, pp. 179-183, Italy, July 2010.

[15] C. Aouadi, A. Abouloifa, A. Hamdoun, and Y. Boussairi, "Backstepping Based Control of PV system Connected to the Grid," International Journal of Computer Applications in Technology, vol. 3, no. 5, 2014.

[16] P. Kumar, U. Das, and S. Chatterjee, "A brief study on control structure of grid connected PV inverter," in Proceedings of the 2016 International Conference on Energy Efficient Technologies for Sustainability, ICEETS 2016, pp. 577-582, India, April 2016.

[17] S. Dhar and P. K. Dash, "A new backstepping finite time sliding mode control of grid connected PV system using multivariable dynamic VSC model," International Journal of Electrical Power \& Energy Systems, vol. 82, pp. 314-330, 2016.

[18] C. L. Trujillo, F. Santamaría, and E. E. Gaona, "Modeling and testing of two-stage grid-connected photovoltaic microinverters," Journal of Renewable Energy, vol. 99, pp. 533-542, 2016.
[19] G. Besançon, J. de León-Morales, and O. Huerta-Guevara, "On adaptive observers for state affine systems," International Journal of Control, vol. 79, no. 6, pp. 581-591, 2006. 

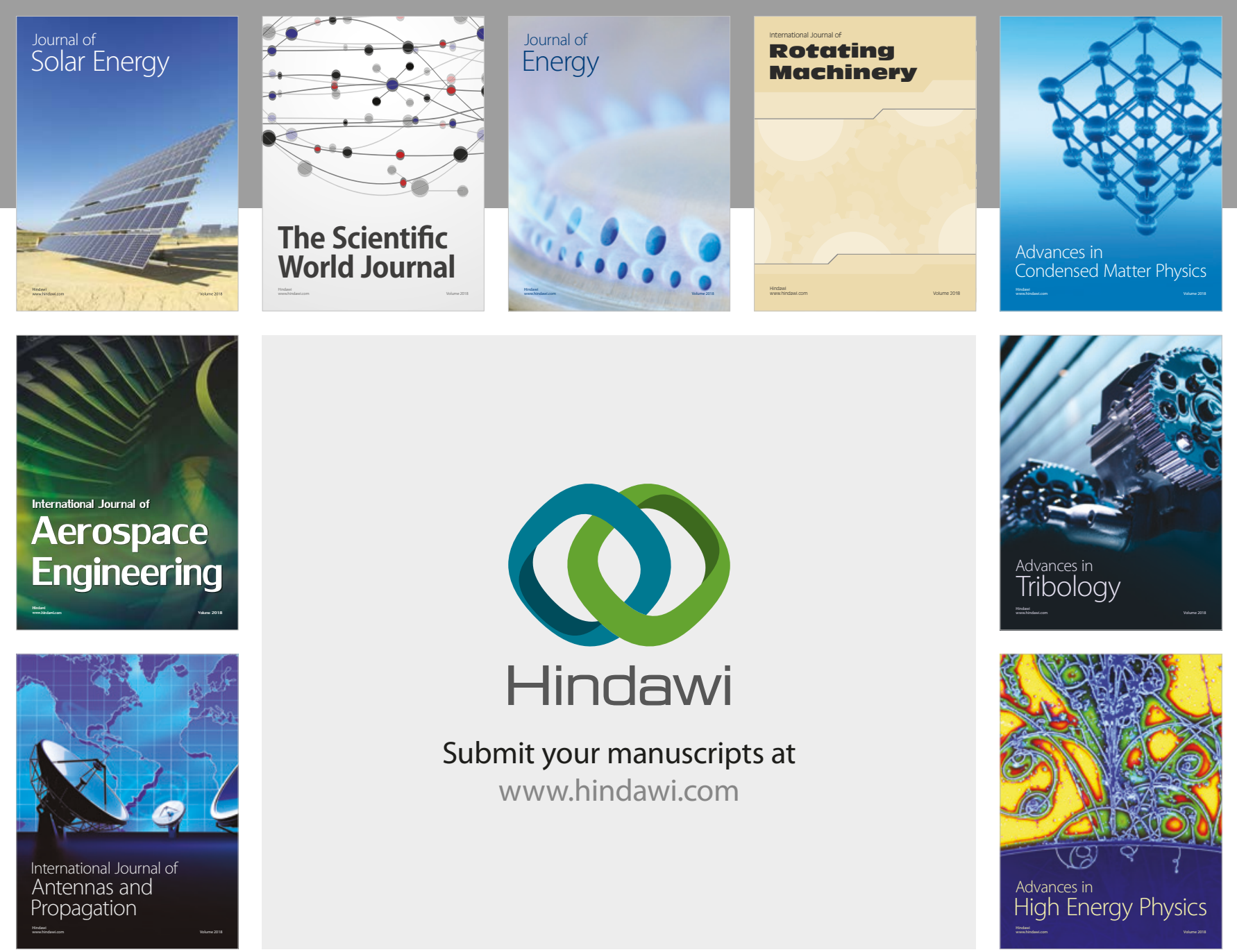

Submit your manuscripts at

www.hindawi.com
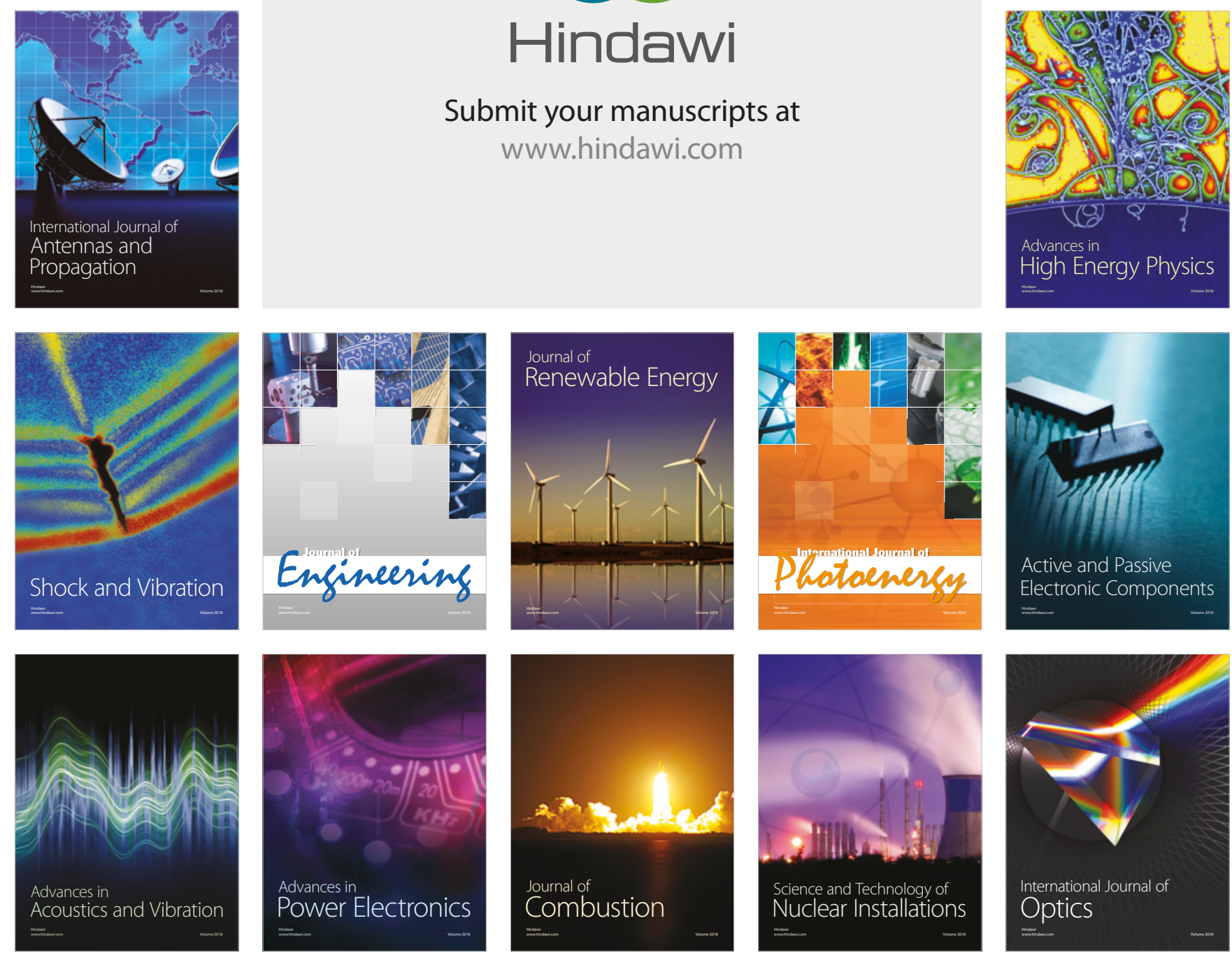